\title{
Composition and diversity of bacteria from giant Asian honeybee Apis dorsata gut
}

\author{
NURDJANNAH JANE NIODE ${ }^{1,2}$, ARYANI ADJI ${ }^{1,2}$, JIMMY RIMBING $^{1}$, MAX TULUNG $^{1}$, \\ TRINA EKAWATI TALLEI ${ }^{3, \varphi}$ \\ ${ }^{1}$ Entomology Program, Graduate School, Universitas Sam Ratulangi. Jl. Kampus Unsrat, Manado 95115, North Sulawesi, Indonesia \\ ${ }^{2}$ Department of Dermatology and Venereology, Faculty of Medicine, Universitas Sam Ratulangi. RD Kandou Hospital, Jl. Raya Tanawangko No. 56, \\ Manado 95163, North Sulawesi, Indonesia. \\ ${ }^{3}$ Department of Biology, Faculty of Mathematics and Natural Sciences, Universitas Sam Ratulangi. Jl. Kampus Unsrat, Manado 95115, North Sulawesi, \\ Indonesia. Tel.: +62-811-4314880, `email: trina_tallei@unsrat.ac.id,
}

Manuscript received: 3 November 2020. Revision accepted: 20 January 2021

\begin{abstract}
Niode NJ, Adji A, Rimbing J, Tulung M, Tallei TE. 2021. Composition and diversity of bacteria from giant Asian honeybee Apis dorsata gut. Biodiversitas 22: 906-912. As a social insect, honeybee possesses a unique gut bacteria community. Therefore, we need to understand the composition and diversity of bacteria in Apis dorsata gut, the largest honeybee species that live in the forest, especially in Southeast Asia. The present study aimed to investigate the gut bacteria of A. dorsata using a metabarcoding approach. The DNA barcode region used in this approach was the V3-V4 region of 16S rRNA. Honeybees were caught in a forest area located in Tareran, South Minahasa, North Sulawesi, Indonesia. There were 11 phyla identified from the gut of A. dorsata. The most abundant phyla were Firmicutes (95.8\%), Proteobacteria (3.7\%), and Actinobacteria (0.4\%). The class Bacilli was responsible for $94.5 \%$ of the total bacterial population, the dominant family was Bacillaceae (87.2\%), and the dominant genus was Bacillus (87\%). Simpson (1-D) 0.24 and Shannon diversity index 0.98 indicated that the diversity of the genera was low. A nonsignificant number of species belong to the lactic acid bacteria was also detected, which may have certain benefits that need to be investigated further.
\end{abstract}

Keywords: 16S rRNA, Apis dorsata, bacteria, gut, honeybee, V3-V4 region

\section{INTRODUCTION}

Pollination is essential for every plant's survival, including vegetables and fruits. The honeybee is one of the insects that play a significant role in pollination. Besides acting as a pollinator, honeybees also produce honey that contains many benefits including rich in energy and nutritional properties. There are nine honeybee species known to this day, including Apis dorsata (Fabricius 1793). Based on its body size, this insect is called the giant honeybee. Apart from their aggressive behavior, this honeybee could make enormous nests with a single comb that hangs from tree branches (Weihmann et al. 2014). The honeybee inhabits Southeast Asia's forests and has never been reported to be seen in urban areas. Out of three, there are two subspecies of $A$. dorsata in Indonesia: $A$. dorsata dorsata and A. $d$. binghami. According to early studies, $A$. $d$. binghami was found only on the island of Sulawesi and its surroundings (Hadisoesilo 2001; Lo et al. 2010). Meanwhile, other subspecies, A.d. breviligula, was found only in the Philippines (Hadisoesilo 2001).

Honeybees are social insects. Their guts possess unique gut microbiota community, caused among others by the high number of individuals within a colony, the food sharing, and the close relationship between colony members. Therefore, these microbiomes are easily propagated from one another among colony members (Engel et al. 2016). Some bacterial species associated with honeybees, are clearly pathogenic, but most species have never been associated with any disease symptoms and their impact on the honeybee is largely unknown (Lamei 2018). Hence, studying the interaction between the microbiome in their gut with its host is very interesting. In previous research, the bacterial community in the midgut of $A$. dorsata has been studied insect development stages (Saraithong et al. 2017). It was reported that Proteobacteria and Firmicutes dominated the midgut, which consisted of four classes: Alphaproteobacteria, Betaproteobacteria, Gammaproteobacteria, and Bacilli. However, the study was not based on a metagenomic approach. So, it is expected that it does not represent the true nature of the microbiome diversity in the gut of A. dorsata. By conducting cultivation, Kwong et al. (2018) reported that they found Apibacter spp. in the gut of A. dorsata. The bacterial species belongs to the phylum Bacteroidetes, reported as endemic to $A$. dorsata and $A$. cerana. Furthermore, it is also described that each honeybee species has a different Apibacter strain symbiont, thus this bacterium is considered to have adapted to its host (Kwong et al. 2017).

A direct method without microbial culture was best to apply to study the gut bacterial diversity and community structure of $A$. dorsata. Not all of these bacteria could be cultured, as reported by several previous researchers (Tajabadi et al. 2011; Evans and Armstrong 2006). Lombogia et al. (2020) has reported that the dominant bacteria in the gut of $A$. nigrocinta found in densely populated urban areas were Proteobacteria (58\%), Firmicutes (29\%), and Actinobacteria (8\%). To our 
knowledge, based on the analysis using metagenomics approach, the bacterial composition and diversity in $A$. dorsata gut have not previously been reported. Thus, this study was conducted to further established the topic.

\section{MATERIALS AND METHODS}

\section{Sampling location}

One honeybee worker of $A$. dorsata was captured in the forest near Rumoong Atas Village, Tareran Sub-district, South Minahasa District (1.2241455, 124.7356518). The identification result of the honeybee based on partial COI gene sequence has been submitted to GenBank (https://www.ncbi.nlm.nih.gov/nuccore/MT233417).

\section{Sample preparation}

Sample preparation was carried out accordingly with the protocol performed by Lombogia et al. (2020). The surface of the bees was sterilized by immersing the entire body of the bee into $1.0 \%$ hypochlorite solution for 10 minutes, then immersed into $70 \%$ ethanol for 2 minutes. After that, the bee's body was rinsed using sterile distilled water three times, then dried using clean tissue paper. The bee's body was dissected under a sterile condition using a sterile scalpel. The gut was put into a sterile Eppendorf tube.

\section{gDNA extraction and metabarcoding process}

The honeybee gut was homogenized using FastPrep-24 Instrument at $4 \mathrm{~m} / \mathrm{s}$ for 25 seconds, then extracted using ZymoBiomics DNA Mini Kit (Zymo Research) obtain the gut bacterial gDNA. Furthermore, NanoDrop 1000 (Thermo Scientific, Wilmington, DE, USA) was used to analyze the gDNA to ensure that it was sufficient for the next stage. The V3-V4 hypervariable regions were selected from the 16S rRNA gene for this metabarcoding process. The area was amplified using MyTaq TM HS Red Mix (Bioline, BIO-25044) in Agilent SureCycler 8800 Thermal Cycler. The polymerase chain reaction (PCR) conditions were run as follow: the denaturation began at $95^{\circ} \mathrm{C}$ for 3 min, then followed by 35 cycles of denaturation at $95^{\circ} \mathrm{C}$ for $15 \mathrm{sec}$, annealing at $52^{\circ} \mathrm{C}$ for $30 \mathrm{sec}$, extension at $72^{\circ} \mathrm{C}$ for $45 \mathrm{sec}$, and a final extension to complete the process at $72^{\circ} \mathrm{C}$ for $3 \mathrm{~min}$.

\section{S rRNA library preparation}

The next stage of the metabarcoding process was preparing the $16 \mathrm{~S}$ rRNA amplicon library using the Illumina two-step PCR protocol. Firstly, the V3-V4 regions were generated using Nextera-style tag sequences (overhang sequences) with the following sequences: forward overhang P5-tag: 5'TCGTCGGCAGCGTCA GATGTGTATAAGAGACAG- [locus-specific sequence] and reverse overhang P7-tag: 5'GTCTCGTGAGGACCGG - [locus-specific sequence]. Then, the process was continued using specific Illumina Nextera XT dual indices (Nextera XT i7 index and Nextera XT i5 index) with the following sequences: P5-PCR primary index: 5'AATGATACGGCGACCACCGAGATCTACAC [i5]
TCGTCGGCAGCGTC and P7-PCRG primary index: 5'CAAGCAGAAG i7] GTCTCGTGGGCTCGG. Amplicon sequencing was conducted using Illumina paired-end platform to generate $250 \mathrm{bp}$ paired-end raw reads (Raw PE), merged, and pretreated to obtain clean tags. In order to get effective tags, which was for subsequent analysis, the chimeric sequences in clean tags were removed using UCHIME.

\section{Bioinformatics analysis}

The Effective Tags with the identity of $97 \%$ were clustered and identified to obtain operational taxonomic units (OTUs), which were useful to study the microbial community composition in each sample (Tallei et al. 2019). Necessary information of different samples such as effective tags, low-frequency tags, and tags annotation data was collected while constructing OTUs.

\section{Sequencing data processing}

The sequenced data processing was carried out accordingly following the previous procedure conducted by Kusumawaty et al. (2020) and Lombogia et al. (2020). The primary sequence was separated from the 16S rRNA barcode region on paired-end reads. This area was then merged using FLASH V1.2.7 (http://ccb.jhu.edu/software/FLASH/) to generate raw tags, which then filtered to obtain clean tags according to the Qiime (V1.7.0). The gold database was used as a reference for clean tags comparison. Chimera sequences in clean tags were detected using the UCHIME algorithm before removal to finally obtain the effective tags.

\section{OTU clustering and taxonomic annotation}

This process was carried out using Uparse Software v7.0.1001. Sequences were clustered to the same OTUs if the similarity index reached $\geq 97 \%$. Annotations were then obtained based on the screening of for each OTU. Species annotations for each representative sequence were obtained from the SSU rRNA database (SILVA Database (http://www.arb-silva.de/) using Mothur software, so that species annotations were obtained for each taxonomic rank (Threshold: $0.8 \sim 1$ ) commenced from kingdom till species. Phylogenetic relationships of all OTUs were constructed using MUSCLE v3.8.31.

\section{Microbial community analysis}

Relative abundance was obtained from taxonomic annotations. This could be illustrated by making pie charts for phylum and genus/species, so the most abundant taxa and their proportion in the sample classification level could be obtained visually.

\section{Alpha diversity analysis}

QIIME (Version 1.7.0) software was used to calculate the alpha bacterial diversity obtained from the A. dorsata gut, which included Simpson (1-D) and Shannon-Wiener (H') indices (Fatimawali et al. 2020). 


\section{Construction of genus evolutionary tree}

The tree was constructed by using NJ methods based on 100 top genera and provided by vendor based on amplicon sequences (region V3-V4). The sequence alignment was conducted using PyNAST software (Version 1.2) and compared with the "core set" dataset in the GreenGene database.

\section{RESULTS AND DISCUSSION}

The bacterial community that inhabits the insect digestive system serves a significant function for its host's health. Therefore, a slight disturbance in the balance of the bacterial community will affect the insect's health and survival (Cariveau et al. 2014). As one of the social insects, honeybee has a microbiome community that is mostly limited to the gut. It is mainly transmitted through social interactions and helps metabolize dietary carbohydrates and protect against pathogens (Raymann and Moran 2018). This microbiota is very dynamic and adaptive because it is influenced by several factors, such as nutrition, the hive environment, social interactions, and the age of the honeybees, while the composition follows seasonal patterns (Lamei 2018).

The presence of symbiont bacteria communities in the gut of A. dorsata was analyzed using the metabarcoding approach. The DNA barcode region used in this approach was V3-V4 which is a hypervariable region of $16 \mathrm{~S}$ rRNA. The result of this metabarcoding shows a total of 11 phyla that can be identified from the gut of $A$. dorsata (Table 1). The most abundant phyla are originated from Firmicutes $(95.8 \%)$, followed by Proteobacteria (3.7\%), and Actinobacteria $(0.4 \%)$, as well as other phyla with very insignificant numbers (Figure 1). This study has generated substantially different results from those found by

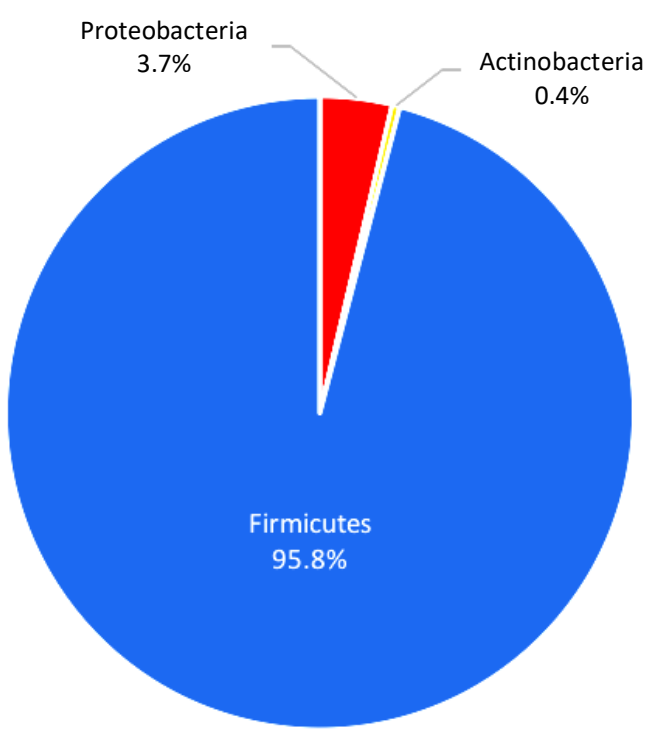

Figure 1. Relative abundance of phyla in the of Apis dorsata dorsata by using metabarcoding approach
Lombogia et al. (2020) in the gut of $A$. nigrocinta, in which the dominant phyla are Proteobacteria (58\%), Firmicutes (29\%), Actinobacteria (8\%), and Bacteroidetes (4\%). A similar result has also been listed by Yun et al. (2018), which the dominant phyla are Proteobacteria (62.1\%) and Firmicutes $(20.7 \%)$. Other researchers have also agreed that the dominating phyla in the honeybee gut consist of Firmicutes, Actinobacteria, and Proteobacteria (Jain et al. 2018; Martinson et al. 2011; and Moran et al. 2012). The relative and absolute abundance of bee communities and their interactions with each other will determine the overall contribution of the microbiome to the health of its hosts (Engel et al. 2016).

Simpson's (1-D) value of 0.23 indicates low phylum diversity in the gut of $A$. dorsata, and there is a dominating taxon in the community (Dominance index: 0.77). Several studies have shown that these results vary, depending on the honeybee caste itself, whether foraging bees or queen (Lombogia et al. 2020).

The class Bacilli is responsible for $94.5 \%$ of the total bacterial population, followed by Gammaproteobacteria (1.8\%), Alphaproteobacteria (1.7\%), and Clostridia (1.1\%). The dominant family is Bacillaceae (87.2\%), later Planococcaceae $(6.5 \%)$. Other families are also detected with insignificant numbers, namely Rhizobiaceae (1.6\%), Orbaceae $(0.9 \%), \quad$ Staphylococcaceae $(0.6 \%)$, Lachnospiraceae $0.5 \%$ ), and Moraxellaceae $(0.5 \%)$. The dominant genus is Bacillus (87\%) and several genera are detected in small numbers, such as Lysinibacillus (6\%), Gilliamella (0.9\%), Staphylococcus (0.6\%), Acinetobacter (0.5\%), Bifidobacterium (0.4\%), Faecalibacterium (0.2\%), and Blautia (0.2\%) (Figure 2). This result is very different from the bacteria in the gut of $A$. nigrocincta found in densely populated areas in the city of Manado (Lombogia et al., 2020). Bifidobacterium has been found with a percentage of $8 \%$ in A. nigrocincta (Lombogia et al. 2020) and $3.34 \%$ in A. mellifera (Wang et al. 2020).

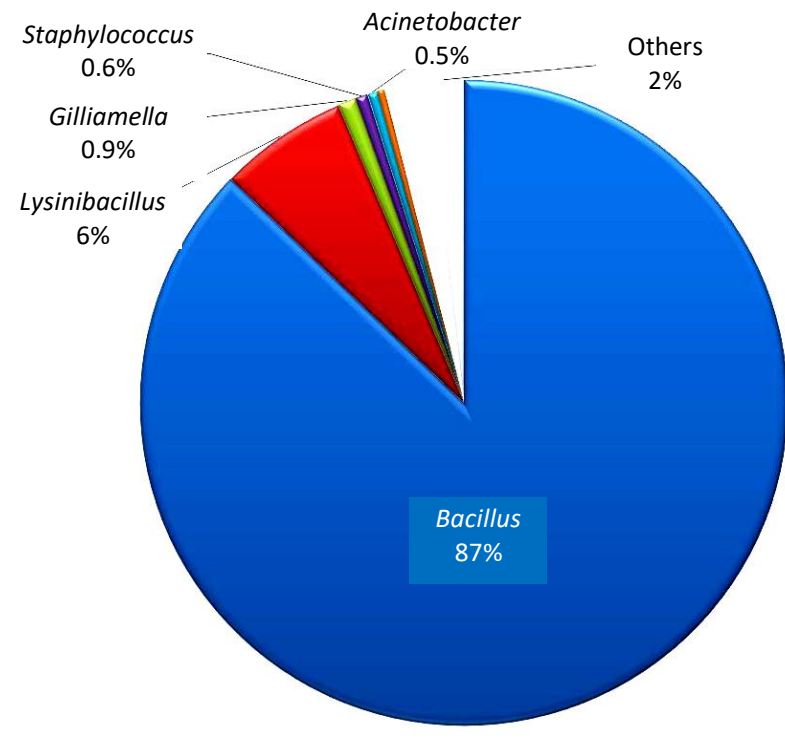

Figure 2. Relative abundance of genera in the gut of Apis dorsata dorsata 
Table 1. Relative abundant of phyla in gut of Apis dorsata dorsata

\begin{tabular}{lc}
\hline Phylum & Relative abundance \\
\hline Firmicutes & 0.95766 \\
Proteobacteria & 0.03652 \\
Actinobacteria & 0.00438 \\
Bacteroidetes & 0.00073 \\
Chloroflexi & 0.00026 \\
Acidobacteria & 0.00021 \\
Gemmatimonadetes & 0.00009 \\
Planctomycetes & 0.00003 \\
GAL15 & 0.00003 \\
Cyanobacteria & 0,00002 \\
Verrucomicrobia & 0.00001 \\
Others & 0,00006 \\
\hline
\end{tabular}

The abundance of Bacillus in the gut of A. dorsata is presumably related to the flowering season in the area where the specimen is found. The sampling area was located at an altitude of about 600 meters above sea level. The vegetation was dominated by Arenga pinnata (L.), Piper aduncum (L.), Syzygium aromaticum, and bushes. Wang et al. (2015) have reported that Bacillus dominated the gut of A. mellifera during the flowering season of the rape plant (Brassicaceae). They have also proposed a hypothesis that the presence and abundance of microbes in the gut of bees were closely related to the availability of feed around them, in which these microbes help process the feed. Functionally, too, these microbes secreted enzymes involved in the metabolization of bee feed. In their research, $\mathrm{Wu}$ et al. (2014) have also found abundant amount of Bacillus in Japanese honeybee's gut. Likewise, the European honeybee, A. mellifera, has been reported to contain many Bacillus species in their guts (Evans and Armstrong 2005). These results may have implied that members of the genus Bacillus have existed in the gut of Apis spp. (Wu et al. 2014). Most studies have found that Bacillus provides benefits for honeybees in pollen fermentation and food protection and disease prevention (Wu 2014). Research by Khan et al. (2020) has shown that Bacillus isolated from the intestine of A. mellifera can inhibit chalkbrood pathogens. Through gluconic acid production, Bacillus senegalensis can control the mushroom chalkbrood Ascosphaera apis. Research by Sabaté et al. (2009) has found that B. subtilis isolated from honeybees' gut can inhibit pathogens Paenobacillus larvae and $A$. apis. This is because the G2III strain of B. subtilis produces surfactin (bacterial cyclic lipopeptide), a very strong surfactant, which is usually used as an antibiotic. A similar case was also found in B. licheniformis isolated from $A$. $m$. jemenitica. This bacterium reduced the mortality rate of bee larvae infected with $P$. larvae (AlGhamdi et al. 2018). Ngalimat et al. (2019) found many Bacillus species isolated from the stingless bee (Heterotrigona sp.) had many activities such as proteolytic, lipolytic, and cellulolytic. Also, one of the strains, $B$. amyloliquefaciens PD9, showed broad-spectrum antimicrobial activity. Kacaniova et al. (2019) have reported $B$. cereus, $B$. megatherium, $B$. olerenius, and $B$. thuringiensis isolated from the gut of $A$. mellifera had antimicrobial activity against $P$. larvae. Bacillus is also a probiotic group member (Niode et al. 2020). Zulkhairi Amin et al. (2019) have suggested that the Bacillus strain isolated from the stingless bee has probiotic potential. The probiotic Bacillus can eliminate Methicillin-resistant Staphylococcus aureus (Piewngam et al. 2018), while B. cereus isolated from the gut of $A$. nigrocincta can inhibit $S$. aureus (Lombogia et al. 2020).

Blot et al. (2019) reported that Lysinibacillus was also found in the gut of A. mellifera. In the gut of A. dorsata, the species found was L. sphaericus. This bacterium, formerly known as B. sphaericus, is usually found in the soil and has a larvicidal effect on mosquitoes (Culex and Anopheles) and is therefore suggested to be a pathogenic insect (Berry 2012). In addition, this species is reported to have antifungal activity (Naureen et al. 2017). They serve as a nutritional ingredient that increases the ability to fix nitrogen, nitrify, and solubilize phosphorus (AquirreMonroy et al. 2019). It produces bacteriocins against foodborne bacterial and fungal pathogens (Ahmad et al. 2014). Thus, it is thought that the presence of $L$. sphaericus in a sufficiently large amount does have an important role for A. dorsata, which is to digest nutrients and protect the host's gut.

Gilliamella apicola is taken $1 \%$ of the bacterial community. According to Zheng et al. (2016), this species is one of the core bacterial species in the gut of the Apis spp. and plays a role in carbohydrate metabolism. Genomic analysis has identified various genes in the $G$. apicola strain, which involve sugar absorption and fermentation (Alatawy et al. 2020). G. apicola strain contains many sugar transporters and sugar utilization pathways (Moran 2015). Engel et al. (2012) found an abundance of genes that process carbohydrates, especially in the $G$. apicola strain isolated from the gut of worker bee communities. In some $G$. apicola strains, pectate lyase that digests pectin in the pollen cell walls was present, while others were absent. This suggests that certain strains in individual worker bees or in colonies can affect bees' nutritional ecology or may function to neutralize food toxins (Moran 2015).

The relative abundance of the genus Bacillus and Lysinibacillus can also be seen in the phylogenetic diagram in Figure 3. Based on this diagram, it is confirmed that there are a considerable number of genera/species. With 194 genera/species observed, Simpson (1-D) 0.24 indicates that the diversity of genus/species in the gut is low, and with a Dominance index value of 0.76 , there is a genus/species that dominates the community. The Shannon diversity index obtained was 0.98 , indicating that the diversity of the genus is low. This is because although the richness of the taxa is relatively high, the evenness is low, and therefore the diversity of genus/species is low. Kirsten et al. (2020) have suggested that the high level of diversity of the microbiota in the gut of A. mellifera can facilitate foraging on a wider variety of pollen sources to adapt more quickly to environmental condition dynamics. However, this high diversity can lead to increased gut microbiota competition. On the other hand, the low gut microbiota diversity of bees may contain various strains adapted to more favorable local conditions. 


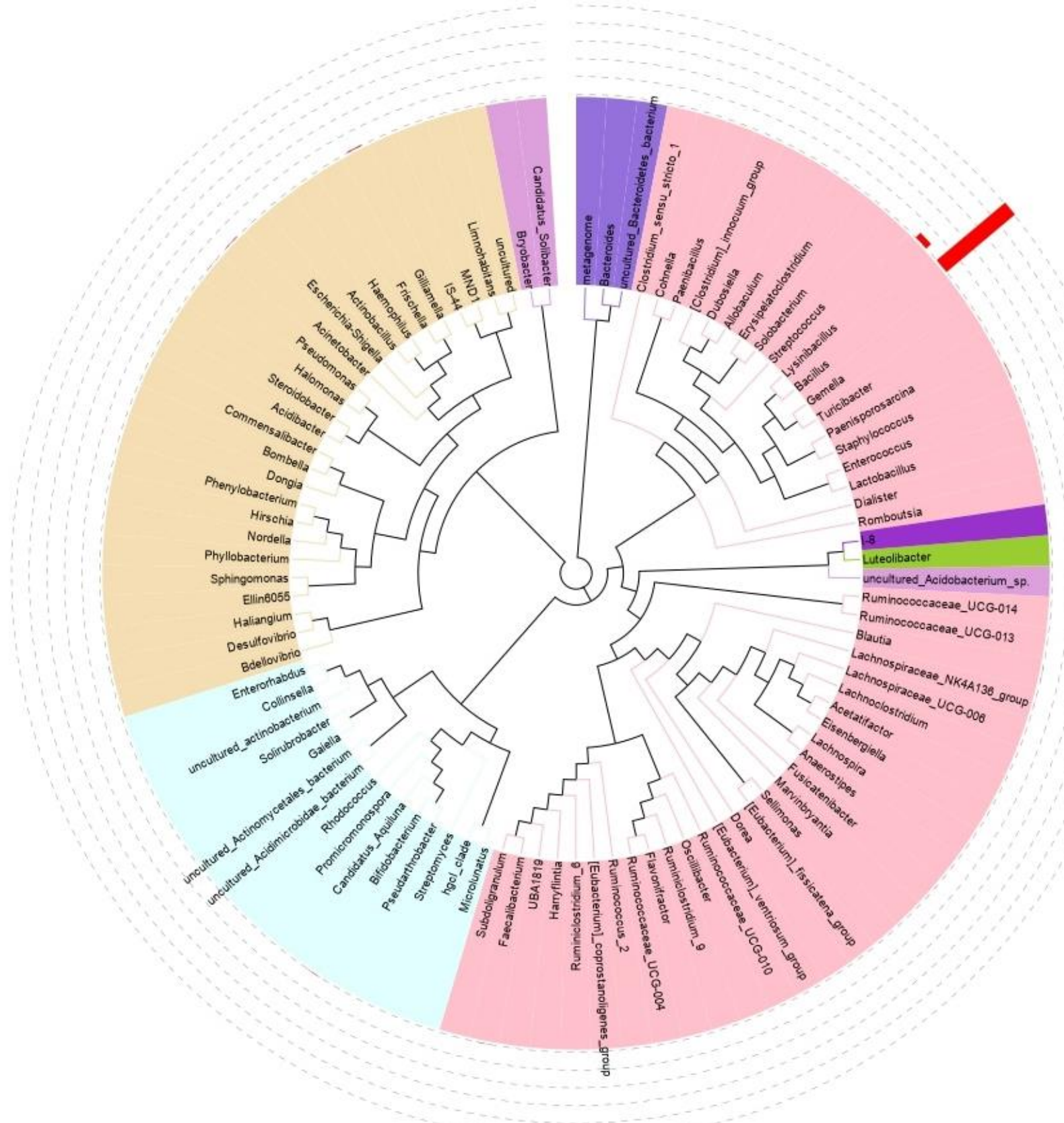

Figure 3. Genus evolutionary tree by using NJ methods. Red bars indicate the relative abundance of the taxa. Different colors of the branches represent different phyla. Relative abundance of each genus in each group is displayed outside the circle

Faecalibacterium and Bifidobacterium are 2 of 10 genera abundant in the gut of Apis mellifera (Wang et al. 2020). Faecalibacterium prausnitzii, which is the only species in the genus Faecalibacterium, is relatively abundant in the healthy human gut (Laursen et al. 2017) and they help in balancing the immune system (Miquel et al. 2013). This species can metabolize fiber which helps in energy conservation and anti-inflammatory (Hiippala et al. 2018).

Bifidobacterium can produce pectin-degrading enzymes, glycoside hydrolase, and Polysaccharide lyase which can degrade complex carbohydrates (Zheng et al. 2019; Wang et al. 2020). The striking differences in the composition of the bacteria inhabiting the A. dorsata gut compared to other honey bees can be attributed to the substrate needed by these bees. This is also closely related to the ecological niche in which these bees live. Hence the structure, composition, and abundance of bacteria in the gut are strongly influenced by food sources.

In conclusion, this study shows the bacterial community's composition and diversity in A. dorsata gut using the V3-V4 hypervariable region of 16S rRNA gene 
marker. Firmicutes dominated most of the phyla, while Bacilli dominated the bacterial class. Relative abundance was found in the genera Bacillus and Lysinibacillus. Simpson (1-D) 0.24 and Shannon diversity index 0.98 indicated low genus diversity. This study can provide data on the microbiome's diversity in the gut of A. dorsata. However, further research will be required to determine the specific relationship between the gut microbiome of $A$. dorsata, its host, and its ecological niche.

\section{ACKNOWLEDGEMENTS}

This research is part of the Doctoral Dissertation Research Grant funded by the Indonesian Ministry of Research and Technology/National Research and Innovation Agency for Fiscal Year 2020 through the Directorate of Research and Community Service.

\section{REFERENCES}

Aguirre-Monroy AM, Santana-Martínez JC, Dussán J. 2019 Lysinibacillus sphaericus as a nutrient enhancer during fire-impacted soil replantation. Appl Environ Soil Sci 2019: 3075153. DOI: 10.1155/2019/3075153.

Ahmad V, Iqbal AM, Haseeb M, Khan MS. 2014. Antimicrobial potential of bacteriocin producing Lysinibacillus jx416856 against foodborne bacterial and fungal pathogens, isolated from fruits and vegetable waste. Anaerob (27): 87-95.

Alatawy M, Al-Attas SG, Assagaf AI, Al-Shehri A, Alghamdi KM, Ahmed Bahieldin A. 2020. Gut microbial communities of adult honey bee workers (Apis mellifera). Biosci Biotechnol Res Asia 17 (2): 353 362 .

Al-Ghamdi A, Ali Khan K, Javed AM, Almasaudi S, Al-Kahtani S. 2018. Effect of gut bacterial isolates from Apis mellifera jemenitica on Paenibacillus larvae infected bee larvae. Saudi J Biol Sci 25: 383 387.

Berry C. 2012. The bacterium, Lysinibacillus sphaericus, as an insect pathogen. J Invertebr Pathol 109 (1): 1-10.

Blot N, Veillat L, Rouze' R, Delatte H. 2019. Glyphosate, but not its metabolite AMPA, alters the honeybee gut microbiota. PLoS ONE 14 (4): e0215466. DOI: 10.1371/journal.pone.0215466

Cariveau DP, Elijah PJ, Koch H, Winfree R, Moran NA 2014. Variation in gut microbial communities and its association with pathogen infection in wild bumble bees (Bombus). ISME J 8: 2369-2379.

Engel P, Kwong WK, McFrederick Q, Anderson KE, Barribeau SM, Chandler JA, Cornman RS, Dainat J, de Miranda JR, Doublet V, Emery O, Evans JD, Farinelli L, Flenniken ML, Granberg F, Grasis JA, Gauthier L, Hayer J, Koch H, Kocher S, Martinson VG, Moran N, Munoz-Torres M, Newton I, Paxton RJ, Powell E, Sadd BM, SchmidHempel P, Schmid-Hempel R, Song SJ, Schwarz RS, vanEngelsdorp D, Dainat B. 2016. The bee microbiome: impact on bee health and model for evolution and ecology of host-microbe interactions. mBio 7 (2): e02164-15. DOI: 10.1128/mBio.02164-15.

Engel P, Martinson VG, Moran NA. 2012. Functional diversity within the simple gut microbiota of the honey bee. Proc Natl Acad Sci USA 109: 11002-11007.

Evans JD, Armstrong TN. 2005. Inhibition of the American foulbrood bacterium, Paenibacillus larvae, by bacteria isolated from honey bees. J Apic Res 44: 168-171.

Evans JD, Armstrong TN. 2006. Antagonistic interactions between honey bee bacterial symbionts and implications for disease. BMC Ecol 6: 4 . DOI: $10.1186 / 1472-6785-6-4$.

Fatimawali, Kepel BJ, Gani MA, Tallei TE. 2020. Comparison of bacterial community structure and diversity in traditional gold mining waste disposal site and rice field by using a metabarcoding approach Intl J Microbiol 2020: 1858732. DOI: 10.1155/2020/1858732.

Hadisoesilo S. 2001. The diversity of indigenous honey bee species of Indonesia. Biodiversitas 2 (1): 123-128. [Indonesian]
Hiippala K, Jouhten H, Ronkainen A, Hartikainen A, Kainulainen V, Jalanka J, Satokari R. 2018. The potential of gut commensals in reinforcing intestinal barrier function and alleviating inflammation. Nutrients 10 (8): 988.

Jain A, Li XH, Chen WN. 2018. Similarities and differences in gut microbiome composition correlate with dietary patterns of Indian and Chinese adults. AMB Express 8 (1): 104. DOI: 10.1186/s13568-0180632-1.

Kačániová M, Gasper J, Terentjeva M. 2019. Antagonistic effect of gut microbiota of honeybee (Apis mellifera) against causative agent of American foulbrood Paenibacillus larvae. J Microbiol Biotechnol Food Sci 9: 478-481.

Khan S, Somerville D, Frese M, Nayudu M. 2020. Environmental gut bacteria in European honey bees (Apis mellifera) from Australia and their relationship to the chalkbrood disease. PLoS ONE 15 (8): e0238252. DOI: 10.1371/journal.pone.0238252.

Kirsten ME, Shota S, Ryo M, Philipp E. 2020. Vast differences in strainlevel diversity in the gut microbiota of two closely related honey bee species. Curr Biol 30 (13): 2520-2531.

Kusumawaty D, Surtikanti HK, Hernawati, Tallei TE. 2020. Data on community structure and diversity of the intestinal bacteria in elver and fingerling stages of wild Indonesian shortfin eel (Anguilla bicolor bicolor). Data in Brief 29: 105299.

Kwong WK, Mancenido AL, Moran NA. 2017. Immune system stimulation by the native gut microbiota of honey bees. R Soc Open Sci 4 (2): 170003

Kwong WK, Steele MI, Moran NA. 2018. Genome sequences of Apibacter spp., gut symbionts of Asian honey bees. Genome Biol Evol 10: 1174-1179.

Lamei S. 2018. The Effect of Honeybee-Specific Lactic Acid Bacteria on American Foulbrood Disease of Honeybees. [Dissertation]. Lund University, Swedish.

Laursen MF, Laursen RP, Larnkjær A, Mølgaard C, Michaelsen KF, Frøkiær H, Bahl MI, Licht TR. 2017. Faecalibacterium gut colonization is accelerated by presence of older siblings. mSphere. 2 (6): e00448-17. DOI: 10.1128/mSphere.00448-17.

Lo N, Gloag RS, Anderson DL, Oldroyd BP. 2010. A molecular phylogeny of the genus Apis suggests that the giant honey bee of the Philippines, A. breviligula Maa, and the Plains Honey Bee of southern India, A. indica Fabricius, are valid species. Syst Entomol 35: 226233.

Lombogia CA, Tulung M, Posangi J, Tallei TE. 2020. Bacterial composition, community structure, and diversity in Apis nigrocincta Gut. Intl J Microbiol 2020: 6906921. DOI: 10.1155/2020/6906921.

Lombogia CA, Tulung M. Posangi J, Tallei TE. 2020. Antibacterial activities of culture-dependent bacteria isolated from Apis nigrocincta gut. Open Microbiol J 14: 72-76.

Martinson VG, Danforth BN, Minckley RL, Rueppell O, Tingek S, Moran NA. 2011. A simple and distinctive microbiota associated with honey bees and bumble bees. Mol Ecol 20: 619-628.

Miquel S, Martín R, Rossi O, Bermúdez-Humarán LG, Chatel JM, Sokol H, Thomas M, Wells JM, Langella P. 2013. Faecalibacterium prausnitzii and human intestinal health. Curr Opin Microbiol 16 (3): 255-261.

Moran NA, Hansen AK, Powell JE, Sabree ZL. 2012. Distinctive gut microbiota of honey bees assessed using deep sampling from individual worker bees. PLoS ONE 7: e0036393. DOI: 10.1371/journal.pone.0036393.

Moran NA. 2015. Genomics of the honey bee microbiome. Curr Opin Insect Sci 10: 22-28.

Naureen Z, Rehman NU, Hussain H, Hussain J, Gilani SA, Al Housni SK, Mabood F, Khan AL, Farooq S, Abbas G, Harrasi AA. 2017 Exploring the potentials of Lysinibacillus sphaericus ZA9 for plant growth promotion and biocontrol activities against phytopathogenic fungi. Front Microbiol 8: 1477. DOI: 10.3389/fmicb.2017.01477.

Ngalimat M S, Raja Abd Rahman R, Yusof MT, Syahir A, Sabri S. 2019. Characterization of bacteria isolated from the stingless bee, Heterotrigona itama, honey, bee bread and propolis. Peer J 7: e7478. DOI: $10.7717 /$ peerj.7478

Niode NJ, Salaki, CL, Rumokoy LJM, Tallei TE. 2020. Lactic acid bacteria from honey bees digestive tract and their potential as probiotics. In: Advances in Biological Sciences Research, volume 8; International Conference and the 10th Congress of the Entomological Society of Indonesia (ICCESI 2019), Bali, 6-9 October 2019. [Indonesian] 
Piewngam P, Zheng Y, Nguyen TH, Dickey SW, Joo HS, Villaruz AE, Glose KA, Fisher EL, Hunt RL, Li B, Chiou J, Pharkjaksu S, Khongthong S, Cheung GYC, Kiratisin P, Otto M. 2018. Pathogen elimination by probiotic Bacillus via signalling interference. Nature 562: 532-537.

Raymann K, Moran NA. 2018. The role of the gut microbiome in health and disease of adult honey bee workers. Curr Opin Insect Sci 26: $97-$ 104.

Sabaté DC, Carrillo L, Audisio M C. 2009. Inhibition of Paenibacillus larvae and Ascosphaera apis by Bacillus subtilis isolated from honeybee gut and honey samples. Res Microbiol 160: 193-199.

Saraithong P, Li Y, Saenphet K, Chen Z, Chantawannakul P. 2017 Midgut bacterial communities in the giant Asian honeybee (Apis dorsata) across 4 developmental stages: A comparative study. Insect Sci 24: 81-92.

Tajabadi N, Mardan M, Abdul Manap MY, Shuhaimi M, Meimandipour A, Nateghi L. 2011. Detection and identification of Lactobacillus bacteria found in the honey stomach of the giant honeybee Apis dorsata. Apidologie 42: 642-649.

Tallei TE, Fatimawali, Pelealu JJ. 2019. The data on metagenomic profile of bacterial diversity changes in the different concentrations of fermented romaine lettuce brine. Data in Brief 25: 104190. DOI: 10.1016/j.dib.2019.104190

Wang H, Liu C, Liu Z, Wang Y, Ma L, Xu B. 2020. The different dietary sugars modulate the composition of the gut microbiota in honeybee during overwintering. BMC Microbiol 20: 61. DOI: 10.1186/s12866020-01726-6.
Wang M, Zhao W, Xu H, Wang ZW, He S. 2015. Bacillus in the guts of honey bees (Apis mellifera; Hymenoptera: Apidae) mediate changes in amylase values. Eur J Entomol 112: 619-624.

Weihmann F, Waddoup D, Hötzl T, Kastberger G. 2014. Intraspecific aggression in giant honey bees (Apis dorsata). Insects 5: 689-704.

Wu M, Sugimura Y, Iwata K, Takaya N, Takamatsu D, Kobayashi M, Taylor D, Kimura K, Yoshiyama M. 2014. Inhibitory effect of gut bacteria from the Japanese honey bee, Apis cerana japonica, against Melissococcus plutonius, the causal agent of European foulbrood disease. J Insect Sci 14: 129. DOI: 10.1093/jis/14.1.129.

Yun JH, Jung MJ, Kim PS, Bae JW. 2018. Social status shapes the bacterial and fungal gut communities of the honey bee. Sci Rep 8 . DOI: $10.1038 / \mathrm{s} 41598-018-19860-7$.

Zheng H, Nishida A, Kwong WK, Koch H, Engel P, Steele MI, Moran NA. 2016. Metabolism of toxic sugars by strains of the bee gut symbiont Gilliamella apicola. mBio 7 (6): e01326-16. DOI: 10.1128/mBio.01326-16.

Zheng H, Perreau J, Powell JE, Han B, Zhang Z, Kwong WK, Tringe SG, Moran NA. 2019. Division of labor in honey bee gut microbiota for plant polysaccharide digestion. Proc Natl Acad Sci 116 (51): 2590925916.

Zulkhairi Amin FA, Sabri S, Ismail M, Chan KW, Ismail N, Mohd Esa N, Mohd Lila MA, Zawawi N. 2019. Probiotic properties of Bacillus strains isolated from Stingless bee (Heterotrigona itama) honey collected across Malaysia. Int J Environ Res Publ Health 17 (1): 278. DOI: $10.3390 /$ ijerph17010278. 